\title{
Survival and Clinical Aspects for Patients with Chronic Lymphocytic Leukemia in Kermanshah, Iran
}

\author{
Mehrdad Payandeh ${ }^{1}$, Edris Sadeghi ${ }^{2}$, Masoud Sadeghi ${ }^{3 *}$
}

\begin{abstract}
Chronic lymphocytic leukemia (CLL)is the most common leukemia in adults in Western countries but is relatively rare in Asia. Immune hemolytic anemia, Evan's syndrome, lymphadenopathy, organomegaly and B symptoms are the main complaints of patients in CLL. The present retrospective analysis evaluated a group of 109 patients with CLL over a 9-year period, studying correlations between sex, age and overall survival. The patients were hospitalized in the Clinic of Hematology and Oncology, Kermanshah, Iran, between 2006 and 2014. Data analysis for sex and age was performed using IBM SPSS19 and overall survival was plotted by KaplanMeier plot, Log-rank test in Graph Pad prism 5 Software for five-year periods. The mean age of diagnosis for CLL patients was 60.73 years, $59.6 \%$ male. Survival rate patients was $64 \%$ and mean overall survival was 38.5 months. In the Rai system, fourteen patients $(\mathbf{1 2 . 8 \%})$ had stage III and twenty eight patients (25.7\%) had stage IV. Most frequent clinical features in patients with CLL were lymphadenopathy (38.7\%) and organomegaly $(34 \%)$, respectively. There is not relationship between sex and age in patients but overall survival rate in females was higher than in males. In Asian countries, CLL is more in male and in age above 60 years. Complaints about lymphadenopathy and virus infection are prevalent.
\end{abstract}

Keywords: Chronic lymphocytic leukemia - age - sex - survival - Kermanshah, Iran

Asian Pac J Cancer Prev, 16 (17), 7987-7990

\section{Introduction}

Chronic lymphocytic leukemia (CLL) is associated with a state of immunosuppression characterized by hypogammaglobulinemia as well as B and T lymphocyte dysfunction(Sarkar et al., 2014).

CLL is a disease of the elderly, yet few clinical trials include a significant number of older patients, and outcomes after specific therapies can be different depending on age(Woyach et al., 2013). The median survival for all patients with CLL is widely variable and, depending on prognostic factors, ranges from 18 months to greater than 10 years (Siddon et al., 2013), but overall survival is worse in older patients (Stephens et al., 2012).

Staging is useful in CLL to predict prognosis and also to stratify patients to achieve comparisons for interpreting specific treatment results. Anemia and thrombocytopenia are the major adverse prognostic variables. CLL has no standard staging system. The Rai staging system has from stage 0 to IV and the Binet classification has stage A, stage B and stage C (Rai et al, 1975; Binet et al, 1981) .

Autoimmune hemolytic anemia (AIHA) is the clinical condition in which antibodies of immunoglobulin $\mathrm{G}$ (IgG) and/or immunoglobulin M (IgM) bind to red cell surface antigens and initiate red cell destruction via the complement system and the reticulo-endothelial system
(Chaudhary et al., 2014). Evan's Syndrome (ES) is the rare simultaneous or subsequent development of immune thrombocytopenia purpura (ITP) and AIHA (Dosi et al., 2012).

Lymphadenopathy refers to lymph nodes which are abnormal in size, number or consistency and is often used as a synonym for swollen or enlarged lymph nodes. Common causes of lymphadenopathy are infection, autoimmune disease, or malignancy (King et al., 2014).

B symptoms refer to systemic symptoms of fever, night sweats, and weight loss which can be associated with both Hodgkin's lymphoma and non-Hodgkin's lymphoma and also organomegaly means hepatomegaly and/or splenomegaly.

The study aims to evaluate a group of 109 patients with CLL in Western Iran (Kermanshah) on a 9-year period, and studying correlation between sex, age and overall survival in patients comparing with other countries in Asia.

\section{Materials and Methods}

In this study, we did a retrospective analysis from 109 CLL patients that referred to Clinic of HematologyOncology, Kermanshah, Iran, between January 2006 and March 2014. For all of patients were calculated sex, age, survival, AIHA, Evan's syndrome, lymphadenopathy, 
Mehrdad Payandeh et al

organomegaly, B symptoms, white blood cell, hemoglobin and platelet by patient or pathology reports or laboratory tests.

\section{Statistical analysis}

Data analysis for sex and age was performed using IBM SPSS software version 19. The p-value was calculated with $\mathrm{T}$ - test that $\mathrm{P}<0.05$ was significant. Overall survival (OS) was calculated as the time from diagnosis to death or last contact. Curve of OS was plotted by KaplanMeier plot in Graph Pad prism 5 Software in a five-year period (March 2009 - March 2014) with completing a two-year period and curves of OS for male and female were compared by log-rank test.

\section{Results}

The mean age \pm SD of diagnosis for CLL patients was $60.73 \pm 10.49$ years (range, 21 to 84 years) that 65 patients $(59.6 \%)$ were male and 44 patients $(40.4 \%)$ were female

Table 1. The baseline characteristics in the patients at time of diagnosis of chronic lymphocytic leukemia $(n=109)$

\begin{tabular}{|c|c|c|c|}
\hline $\begin{array}{l}\text { Primary variables } \\
\text { and clinical features }\end{array}$ & $\mathrm{n}(\%)$ & Mean \pm SD & P-value \\
\hline \multirow[t]{2}{*}{ Age } & & $60.73 \pm 10.49$ & \\
\hline & & & $\mathrm{P}>0.05^{*}$ \\
\hline \multicolumn{4}{|l|}{ Sex } \\
\hline Male & $65(59.6)$ & & \\
\hline Female & $44(40.4)$ & & \\
\hline \multicolumn{4}{|l|}{ Stage } \\
\hline 0 & $44(40.4)$ & & \\
\hline 1 & $8(7.4)$ & & \\
\hline 2 & $15(13.7)$ & & \\
\hline 3 & $14(12.8)$ & & \\
\hline 4 & $28(25.7)$ & & \\
\hline $\begin{array}{l}\text { Autoimmune } \\
\text { Hemolytic Anemia }\end{array}$ & $16(15.1)$ & & \\
\hline Evan's Syndrome & $4(3.8)$ & & \\
\hline Lymphadenopathy & $41(38.7)$ & & \\
\hline Organomegaly & $36(34.0)$ & & \\
\hline B Symptoms & 19(19.9) & & \\
\hline
\end{tabular}

* T- test

Table 2. The Primary Clinical Variables in CLL Patients

\begin{tabular}{|c|c|c|}
\hline Clinical features & Mean $\left(\times 10^{3}\right)$ & $\begin{array}{c}\text { Range: }[\text { Min } \\
\text { to Max }] \\
\left(\times 10^{3}\right)\end{array}$ \\
\hline Platelet(count. $\mu$ L-1) & 160 & 6 to 334 \\
\hline Hemoglobin(mg.L-1) & 123 & 39 to 181 \\
\hline $\begin{array}{c}\text { White Blood Cell (count. } \\
\mu \mathrm{L}-1)\end{array}$ & 53 & 2.5 to 300 \\
\hline
\end{tabular}

Table 3. Mean age and Percentage of Male for Chronic Lymphocytic Leukemia in Asian Countries

\begin{tabular}{|c|c|c|c|}
\hline Reference & Area & $\begin{array}{c}\text { Mean } \\
(\text { year }\end{array}$ & $\begin{array}{c}\text { Male } \\
(\%)\end{array}$ \\
\hline The present study & Iran( West) & 60.73 & 59.6 \\
\hline Azarm et al., 2013 & Iran(Center) & 64 & 53 \\
\hline Kermani et al., 2007 & Iran(North) & 63.7 & 69.8 \\
\hline Agrawal et al.,2007 & India & 61 & 79 \\
\hline Durak et al., 2009 & Turkey & 64.3 & 64.5 \\
\hline Osmani et al., 2013 & Pakistan & 59.53 & 79 \\
\hline Iwatani et al., 2014 & Japan & 69.5 & 64.2 \\
\hline Goede et al., 2014 & Russia & 73 & - \\
\hline Pamuk et al., 2004 & Turkey & 63 & 64.5 \\
\hline Aozasa et al., 1991 & Russia & 57.5 & 70.3 \\
\hline
\end{tabular}

Table 4. Mean overall survival and survival rate (5year period) for chronic lymphocytic leukemia in Asian countries

\begin{tabular}{|c|c|c|c|}
\hline Reference & Area & $\begin{array}{c}\text { Mean } \\
\text { (Month) }\end{array}$ & $\begin{array}{c}\text { Survival } \\
\text { Rate (\%) }\end{array}$ \\
\hline The present study & Iran( West) & 38.5 & 64 \\
\hline Pamuk et al., 2004 & Turkey & 48 & 36.5 \\
\hline Zhu et al., 2003 & China & - & 81.8 \\
\hline Wu et al., 2009 & China & 48 & 87.3 \\
\hline Chim et al,2006 & China & - & 72 \\
\hline Gogia et al., 2014 & India & 42 & 51 \\
\hline
\end{tabular}

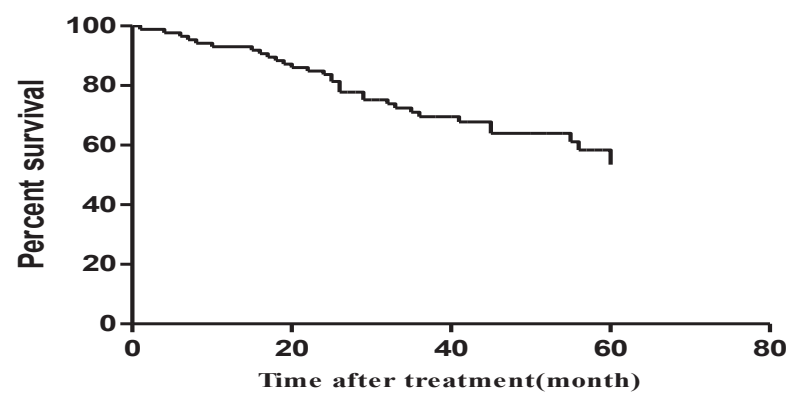

Figure 1. The 5-year overall survival for chronic lymphocytic leukemia for all of patients

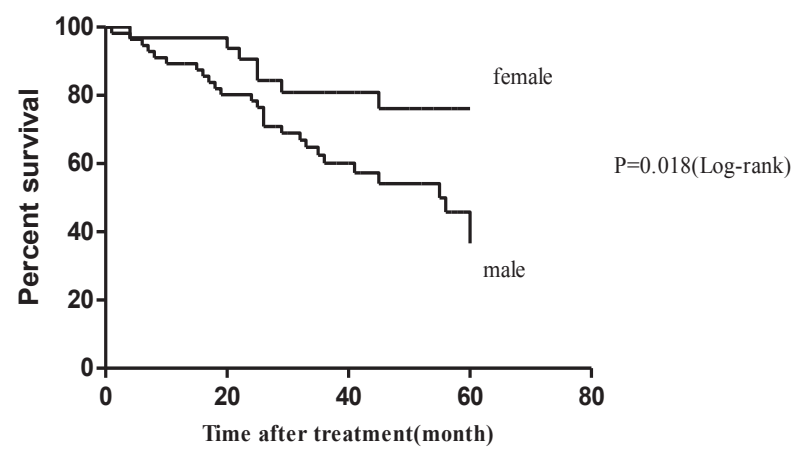

Figure 2. The 5-year overall survival rate for chronic lymphocytic leukemia by sex 
(Table 1). Mean of age for female was higher than male, but there wasn't significant difference between sex and age in patients $(\mathrm{P}>0.05,95 \%$ confidence interval $(\mathrm{CI})-6.03$ to 2.09). Based on Rai system, Forty four patients (40.4\%) in our study had stage 0 and eight patients $(7.4 \%)$, fifteen patients $(13.7 \%)$, fourteen patients $(12.8 \%)$ and twenty eight patients $(25.7 \%)$ are located in stage I, stage II, stage III and stage IV, respectively. Of 109 patients, the 16 patients $(15.1 \%)$ had AIHA, 4 patients $(3.8 \%)$ had Evan's Syndrome, 41 patients (38.7\%) had lymphadenopathy, 36 patients $(34 \%)$ had organomegaly and 19 patients $(17.9 \%)$ had B Symptoms (Table 1).

In our study, the mean of platelet, hemoglobin and WBC were $160 \times 10^{3} / \mu \mathrm{L}, 123 \times 10^{3} \mathrm{mg}$. L- 1 and $53 \times 10^{3}$ $/ \mu \mathrm{L}$, respectively (Table 2 ). Of all patients, 22 patients $(20.8 \%)$ were treated with IVIG and 46 patients $(43.3 \%)$ were treated with vaccine of the Flu.

The 5-year OS (March 2009 - March 2014) for all of patients has been showed in Figure 1. Of 109 patients with CLL, 29 patients died and 23 patients were lost to follow-up before completing a two-year period and should therefore be excluded from the analysis. Survival rate for patients was $64 \%$ and mean of overall survival for 5-year period was 38.5 months.

Figure 2 shows OS rate for men comparing with women. There is a significant difference between sex and OS rate $(\mathrm{P}=0.018,95 \% \mathrm{CI}$ of ratio $1.14-4.65$, Hazard Ratio (HR) 2.31).The survival rate for females is $78 \%$ and for males is $53.5 \%$.

\section{Discussion}

The CLL is the most common leukemia in adults in the Western countries. However, this disease is very rare in Asian countries (Kawamata et al, 2013; Maffei et al, 2014). CLL is caused by the accumulation of a longlived antigen-experienced $\mathrm{B}$ cell clone, of which a small fraction is represented by actively proliferating cells with approximately $1-2 \%$ of cells newly generated each day (Maffei et al., 2014).

Two studies in Iran and our study (Table 3 ) shows that patients mean age of diagnosis is around 60 years, and also majority of patients are males. Results in Iran with other Asian countries in Table 3 are the same.

The Table 4 shows a number of studies for chronic lymphocytic leukemia in Asian countries. The 5-year mean overall survival in three countries is between 40 and 50 months and in our study is less than 40 months but the 5-year survival rate is more than $70 \%$, except Turkey and India.

Our study and other study (Catovsky et al., 2014) show that OS rate in females is higher than males, and in our study this comparison was statistically significant between females and males $(\mathrm{P}<0.05)$. Therefore, it is probably that life conditions (smoking, hard work, etc) in males comparing with females have more affect on the appearance and mortality of CLL. In Western Iran (Kermanshah) majority of males work more than females in hard condition and smoking in males is more. In previous studies were reported that smoking (Muirhead et al., 2009) and quality of life (Shanafelt et al., 2009) influence on development of CLL. The development of AIHA in patients with CLL is associated with specific biological features (Maura et al., 2013). Evan's syndrome and AIHA are two the main autoimmune disorders that Rossignol et al., 2010. Reported in 48 CLL patients, 26 patients (54\%) had AIHA and $8(16.7 \%)$ had Evan's syndrome. Also Mittal et al. (2008). Showed in 31 patients with CLL, 11 patients (35\%) had AIHA and 2(6.4\%) had Evan's Syndrome. In our study that was included 109 patients, 16(15.1\%) of them had AIHA and 4(3.8\%) had Evan's Syndrome. These results show that AIHA in West Iran (Kermanshah) is less than other studies and also Evan's Syndrome is different with them.

A study In India (Gogia et al., 2013) reported that Rai stage distribution in patients with CLL was: Stage 0-6, stage I-20, stage II-36, stage III-5, and stage IV-13 but in our study, more of patients had stage 0 and IV, respectively.

B-CLL is characterized by a high frequency of infections, including those of viral aetiology(Marotta et al., 1988).Infectious complications represent a major cause of morbidity and mortality in patients with CLL. The IVIG is used in a broad spectrum of autoimmune, inflammatory, and primary and secondary immunodeficiencies and the efficacy has been demonstrated in several control studies (Milani et al., 2009). Also, Influenza vaccination is recommended for patients with B-cell chronic lymphocytic leukaemia (CLL) (van der Velden et al., 2001). In our study such as other researches, immunodeficiencies and virus of the Flu were reported in patients and they were treated with IVIG and vaccine of the Flu.

First of all, CLL is a rare case of malignancy in Asian countries and lymphadenopathy and organomegaly, immunodeficiencies and the Flu virus are the main complaints in CLL. Second, in these countries, CLL is more in males and in ages of above 60 years. Third, here is not relationship between sex and age in patients. At last, OS rate in females is higher than males.

\section{Acknowledgements}

The authors thank Mr. Gholami for technical assistance.

\section{References}

Agrawal N, Naithani R, Mahapatra M, et al (2007). Chronic lymphocytic leukemia in India--a clinico-hematological profile. Hematol, 12, 229-33.

Aozasa K, Ohsawa M, Horiuchi K, et al (1991). Intermediate lymphocytic lymphoma: its frequency and characteristics in Japan. J Surg Oncol, 48, 268-71.

Azarm T, Fazilati M, Azarm H, et al (2013). Serum selenium levels in chronic lymphocytic leukemia. Adv Biomed Res, 2,44 .

Binet JL, Auquier A, Dighiero G, et al (1981). A new prognostic classification of chronic lymphocytic leukemia derived from a multivariate survival analysis. Cancer, 48, 198-206.

Catovsky D, Wade R, Else M (2014). The clinical significance of patients' sex in chronic lymphocytic leukemia. Haematologica, 99, 1088-94.

Chaudhary RK, Das SS (2014). Autoimmune hemolytic anemia: From lab to bedside. Asian J Transfus Sci, 8, 5-12. 
Mehrdad Payandeh et al

Chim CS, Fung TK, Wong KF, et al (2006). Frequent DAP kinase but not p14 or Apaf-1 hypermethylation in B-cell chronic lymphocytic leukemia. J Hum Genet, 51, 832-8.

Dosi RV, Ambaliya AP, Patell RD, et al (2012). A case report of Evans Syndrome. Indian J Med Sci, 66, 82-5.

Durak B, Akay OM, Aslan V, et al (2009). Prognostic impact of chromosome alterations detected by FISH in Turkish patients with B-cell chronic lymphocytic leukemia. Cancer Genet Cytogenet, 188, 65-9.

Goede V, Fischer K, Busch R, et al (2014). Obinutuzumab plus chlorambucil in patients with CLL and coexisting conditions. N Engl J Med, 370, 1101-10.

Gogia A, Raina V, Gupta R, et al (2014). Prognostic and predictive significance of smudge cell percentage on routine blood smear in chronic lymphocytic leukemia. Clin Lymphoma Myeloma Leuk, 14, 514-7.

Gogia A, Sharma A, Raina V, et al (2013). Prevalence of ZAP-70 and CD 38 in Indian chronic lymphocytic leukemia patients. Indian J Cancer, 50, 333-6.

Iwatani K, Takata K, Sato Y, et al (2014). Low-grade B-cell lymphoma presenting primarily in the bone marrow. Hum Pathol, 45, 1379-87.

Kawamata N, Moreilhon C, Saitoh T, et al (2013). Genetic differences between Asian and Caucasian chronic lymphocytic leukemia. Int J Oncol, 43, 561-5.

Kermani IA, Dehdilani M, Dolatkhah R (2007). Chronic lymphocytic leukemia in the recent 10 years and treatment effects of Fludarabin. Asian Pac J Cancer Prev, 8, 367-71.

King D, Ramachandra J, Yeomanson D (2014). Lymphadenopathy in children: refer or reassure? Arch Dis Child Educ Pract $E d, 99,101-10$.

Maffei R, Bulgarelli J, Fiorcari S, et al (2014). Endothelin-1 promotes survival and chemoresistance in chronic lymphocytic leukemia B cells through ETA receptor. PLoS One, 9,98818.

Marotta G, Bucalossi A, Galieni P, et al (1998). CD4+/CD45RA+ 'naive' $\mathrm{T}$ cells and immunological response to influenza virus vaccine in B-cell chronic lymphocytic leukaemia patients. Acta Haematol, 99, 18-21.

Maura F, Visco C, Falisi E, et al (2013). B-cell receptor configuration and adverse cytogenetics are associated with autoimmune hemolytic anemia in chronic lymphocytic leukemia. Am J Hematol, 88, 32-6.

Milani C, Dalia SM, Colvin GA (2009). Thromboembolic complications of intravenous immunoglobulin (IVIG) in an immunocompromised patient with chronic lymphocytic leukemia: a case report. Cases J, 2, 9078.

Mittal S, Blaylock MG, Culligan DJ, et al (2008). A high rate of CLL phenotype lymphocytes in autoimmune hemolytic anemia and immune thrombocytopenic purpura. Haematologica, 93, 151-2.

Muirhead CR, O'Hagan JA, Haylock RG, et al (2009). Mortality and cancer incidence following occupational radiation exposure: third analysis of the national registry for radiation workers. Br J Cancer, 100, 206-12.

Osmani AH, Masood N (2013). Single centre study of using bendamustine in the treatment of B-cell malignancies. J Pak Med Assoc, 63, 702-6.

Pamuk ON, Pamuk GE, Soysal T, et al (2004). Chronic lymphocytic leukemia in Turkey: experience of a single center in Istanbul. South Med J, 97, 240-5.

Rai KR, Sawitsky A, Cronkite EP, et al (1975). Clinical staging of chronic lymphocytic leukemia. Blood, 46, 219-34.

Rossignol J, Michallet AS, Oberic L, et al (2011). Rituximabcyclophosphamide-dexamethasone combination in the management of autoimmune cytopenias associated with chronic lymphocytic leukemia. Leukemia, 25, 473-8.
Sarkar PK, Malhotra P, Sriram PS (2014). Rapid progression of pulmonary blastomycosis in an untreated patient of chronic lymphocytic leukemia. Case Rep Med, 2014, 514382.

Shanafelt TD, Bowen DA, Venkat C, et al (2009). The physicianpatient relationship and quality of life: lessons from chronic lymphocytic leukemia. Leuk Res, 33, 263-70.

Siddon AJ, Rinder HM; Education Committee of the Academy of Clinical Laboratory Physicians and Scientists (2013). Pathology consultation on evaluating prognosis in incidental monoclonal lymphocytosis and chronic lymphocytic leukemia. Am J Clin Pathol, 139, 708-12.

Stephens DM, Ruppert AS, Blum K, et al (2012). Flavopiridol treatment of patients aged 70 or older with refractory or relapsed chronic lymphocytic leukemia is a feasible and active therapeutic approach. Haematologica, 97, 423-7.

Van der Velden AM, Mulder AH, Hartkamp A, et al (2001). Influenza virus vaccination and booster in B-cell chronic lymphocytic leukaemia patients. Eur J Intern Med, 12, 420-4.

Woyach JA, Ruppert AS, Rai K, et al (2013). Impact of age on outcomes after initial therapy with chemotherapy and different chemoimmunotherapy regimens in patients with chronic lymphocytic leukemia: results of sequential cancer and leukemia group B studies. J Clin Oncol, 31, 440-7.

Wu T, Li ZJ, Wang YF, et al (2009). [Prognostic factor analysis in 203 patients with chronic lymphocytic leukaemia]. Zhonghua Xue Ye Xue Za Zhi, 30, 435-9.

Zhu Y, Qin Q, Xie Z (2013). Efficacy of oral fludarabine in patients with chronic lymphocytic leukemia/small lymphocytic lymphoma. Zhong Nan Da Xue Xue Bao Yi Xue Ban, 38, 221-4. 